\title{
Combate à Violência e Redução de Danos: Corpo Político da Mulher nas Festas Universitárias
}

\author{
Fighting Violence and Harm Reduction: Political Women's Bodies in The University \\ Festivities
}

\section{Lucha Contra la Violencia y Reducción de Daños: El Cuerpo Político de las Mujeres en las Festividades Universitarias}

\author{
Katia Alexsandra dos Santos ${ }^{1}$ \\ Paula Marques da Silva \\ Bianca Carolline Oconoski Zarpellon \\ Universidade Estadual do Centro-Oeste (UNICENTRO)
}

\begin{abstract}
Resumo
Este artigo teve o objetivo de discutir a temática da violência contra a mulher nas festas universitárias, a partir das ações de um projeto de extensão. Participaram acadêmicas de uma universidade estadual e outros participantes de festas universitárias. A perspectiva teórico-metodológica sustentou-se na articulação entre as perspectivas dos Direitos Humanos, da Redução de Danos e dos Estudos de Gênero. A metodologia organizou-se em capacitação da equipe; divulgação do projeto; realização de grupos com estudantes que frequentam as festas; intervenções em festas universitárias. Os resultados apontam para sensibilização dos atores da comunidade acadêmica no que se refere ao comprometimento ético-político em relação à temática da violência contra mulher nas festas universitárias, bem como reflexão das acadêmicas sobre a questão dos direitos e da autonomia do corpo da mulher na universidade, além da criação de estratégias coletivas de prevenção.

Palavras-chave: relações comunidade-instituição, redução de danos, violência de gênero, direitos humanos
\end{abstract}

\begin{abstract}
This article aimed to discuss the theme of violence against women in university festivities, based on the actions of an extension project. Undergraduate women from a state university and other people of the university festivities participated in the study. The theoretical-methodological perspective was based on the articulation among the Human Rights, Harm Reduction and gender studies perspectives. The methodology was organized from the training of the team; dissemination of the project; formation of groups with students who attended the parties; interventions at university parties. The results point to the sensitization of the actors in the academic community concerning the ethical-political commitment on the matter of violence against women in the scope of university festivities, provided the reflection of the students on the issue of the rights and autonomy of women's bodies in the university, as well as the creation of collective prevention strategies.

Keywords: community-institutional relations, harm reduction, gender-based violence, human
\end{abstract}

\section{Resumen}

Este artículo tuvo el objetivo de discutir el tema de la violencia contra las mujeres en las festividades universitarias, basándose en las acciones de un proyecto de extensión. Los participantes incluyeron académicas de una universidad estatal y otros participantes de fiestas universitarias. La perspectiva teórico-metodológica se basó en la articulación entre los Derechos Humanos, Reducción de Daños y estudios de género. La metodología fue organizada a partir de la formación del equipo; difusión del proyecto; grupos de trabajo con estudiantes que asisten a fiestas; intervenciones en las fiestas universitarias. Los resultados apuntan a la sensibilización de los actores de la comunidad académica con respecto al compromiso ético-político con el tema de la violencia contra las mujeres en las festividades universitarias, y también produjo la reflexión sobre el tema de los derechos y la autonomía de las mujeres en la universidad, así como la creación de estrategias de prevención colectiva.

Palabras clave: relaciones comunidad-institución, reducción de daños, violencia de género, derechos humanos

\footnotetext{
${ }^{1}$ Endereço de contato: PR-153, $\mathrm{Km} 7 \mathrm{~s} / \mathrm{n}$, Riozinho, Irati, PR. Telefone: (42) 3421-3034. E-mail: kalexsandra@unicentro.br
} 


\section{Introdução}

A questão da violência contra a mulher na universidade tem sido discutida apenas recentemente, havendo poucos dados como os divulgados na pesquisa realizada pelo Data Popular e pelo instituto Avon "Violência contra a mulher no ambiente universitário" (2015), cujos resultados apontam que $67 \%$ das mulheres já sofreram algum tipo de violência (sexual, psicológica, moral ou física) nesse ambiente; $12 \%$ relataram que foram forçadas a ingerir bebidas alcoólicas; $11 \%$ foram coagidas a participar de desfiles, leilões e/ou atividades degradantes. Ao serem questionadas sobre situações específicas de violência sexual, 11\% contam que sofreram tentativa de abuso sexual sob efeito de álcool. Em relação aos homens, a pesquisa revela que $27 \%$ dos entrevistados acreditam que, se uma garota tiver bebido demais, abusar dela não é uma forma de violência.

Assim, este artigo teve o objetivo de relatar alguns resultados obtidos a partir de um projeto de extensão intitulado "Combate à violência e Redução de Danos: autonomia e dimensão pública-política do corpo da mulher no cenário acadêmico", divulgado a partir do nome comercial "Redução de Danos no Rolê", ocorrido no ano de 2018 em uma universidade pública do interior do Paraná. O projeto surgiu em meio a denúncias de assédio, violências sexuais, entre outros tipos de violência que ocorrem no contexto universitário, em festas que são promovidas por universitários ou que contam com a participação destes (Santos \& Zarpellon, 2019)².

Os dados justificam o objetivo geral do projeto, que foi o de promover reflexão e discussão acerca da temática da violência contra mulher no cenário das festas universitárias, a partir da perspectiva teórico-metodológica da Redução de Danos em articulação com os Direitos Humanos, trazendo o diferencial do recorte de gênero. Iniciaremos colocando em pauta a questão da violência contra a mulher sob essa perspectiva, para depois inserirmos um tópico sobre a Redução de Danos e, em seguida, sobre as discussões das ações realizadas.

\section{A violência contra as mulheres e a luta pelos Direitos Humanos no Brasil}

Em uma sociedade patriarcal, a condição de existência das mulheres passa por crivos de uma gestão masculina, branca e heterossexual, que define os caminhos e as formas como o corpo da mulher deve se movimentar no espaço público. A mobilidade da mulher envolve historicamente a geografia da segregação e da clausura no espaço privado. Segundo percurso jurídico apresentado por Dias (2017) e por Mendes (2016), nosso Código Civil (Brasil, 2016) é um exemplo paradigmático da obstrução da mulher no espaço público. Este dispositivo legal impedia as mulheres brasileiras de trabalharem e de realizarem movimentações financeiras sem a autorização marital. Os homens eram considerados os chefes da família, possuindo o pátrio poder absoluto. Tal condição jurídica sofre algumas alterações com a Lei 4.142, de 1962, que deliberou o compartilhamento do pátrio poder no âmbito do casamento, eliminando também o regime de autorizações que os homens possuíam em relação à mobilidade social das mulheres brasileiras. As décadas de 1960, 1970 e início da de 1980 foram marcadas pela violência e opressão do regime da ditadura Civil Militar (1964-1985). Nesse

\footnotetext{
${ }^{2}$ Ver capítulo de livro no qual as autoras discorrem acerca de denúncias realizadas na referida instituição, por meio de redes sociais.
} 
período, vários setores da sociedade e movimentos sociais se articulam em prol de reformas políticas e sociais que pudessem inscrever práticas de governo em diagramas jurídicos legais democráticos.

De acordo com Costa (2009), a busca pelo direito à saúde congrega uma diversidade de vozes sociais que constituem a chamada Reforma Sanitária, e é nesse movimento que a noção de saúde ganha sentidos de democracia. A autora nos conta que, no ano de 1986, em decorrência da ampla participação de mulheres na 8a Conferência Nacional de Saúde, ocorre a I Conferência Nacional de Saúde e Direitos da Mulher. Nela foram discutidas pautas sobre direitos sexuais e reprodutivos, legalização do aborto e assistência integral à saúde da mulher na perspectiva da consolidação do Sistema Único de Saúde (SUS). Costa (2009) afirma ainda que as propostas elaboradas no âmbito da Reforma Sanitária, as quais foram amplamente debatidas na 8a Conferência e na consequente Conferência Nacional de Saúde e Direitos da Mulher, foram fundamentais para que a saúde da mulher não ficasse restrita ao campo da regulação da maternidade, fecundidade e reprodução. Essa inflexão nos aponta para a Saúde como um campo de saber interdisciplinar e coletivo que define a saúde da mulher como intrinsecamente ligada à dignidade humana, à cidadania, à participação nos lugares de decisão e deliberação política, à igualdade de direitos, ao direito de gestão do próprio corpo nos domínios do público e do privado. Tal abordagem foi pauta de reivindicação de muitas mulheres que participaram ativamente no processo da nova constituinte (19871988). Mendes (2016) afirma que a força ativista destas mulheres resultou na produção chamada "Carta Aberta das Mulheres aos Constituintes", na qual foram inseridas propostas de igualdade jurídica entre homens e mulheres, de ampliação dos direitos civis, econômicos e sociais das mulheres, direitos reprodutivos, bem como do fim da discriminação sexista no Brasil. Grande parte dessas propostas foi integrada no texto-lei da Constituição de 1988. A Constituição Cidadã trouxe, em seu Título II, os Direitos e as Garantias Fundamentais. No art. 5ㅇ, o texto-lei institui que "todos são iguais perante a lei, sem distinção de qualquer natureza, garantindo-se aos brasileiros e aos estrangeiros residentes no País a inviolabilidade do direito à vida, à liberdade, à igualdade, à segurança e à propriedade" (Brasil, 1988, art. 5).

De acordo com De Tilio (2012), os Direitos Fundamentais Brasileiros têm como base a Declaração Universal dos Direitos Humanos, de 1948. O Brasil é signatário dos principais tratados e convenções internacionais que visam erradicar a violência e discriminação contra mulher. Para o autor, entre esses marcos legais, a Convenção para Eliminação de Todas as Formas de Discriminação contra as Mulheres (CEDAW), realizada em 1979, merece destaque, justamente por que a partir dela a violência contra as mulheres passou a ser reconhecida oficialmente como um crime contra a humanidade.

A violência contra mulher é pauta cotidiana na agenda de variados segmentos sociais no Brasil. No âmbito jurídico-legal, em 2006, é promulgada a lei 11.340/2006, conhecida como a Lei Maria da Penha, a partir da qual foram criados vários dispositivos de enfrentamento e prevenção no campo da violência contra mulher (Lei n. 11.340, 2006). Ainda, segundo De Tilio (2012), em 2005, foi publicado o I Plano Nacional de Políticas para as Mulheres (2005), ampliando o espectro de ações e estratégias político-assistenciais com ênfase na dignidade da mulher brasileira, na igualdade de direitos, no acesso à justiça, à saúde, à educação e à cultura. Não se pode deixar de citar, ainda, a Lei 13.104/15, que altera o Código Penal 
Brasileiro, incluindo o termo feminicídio como homicídio qualificado, em decorrência de crime praticado contra a mulher por razões da condição do sexo feminino. Outro marco fundamental recente refere-se à Lei 13.818/18, que torna crime a importunação sexual. Vale apontar também que, em 2017, ocorreu a 2a Conferência Nacional de Saúde das Mulheres, que reafirmou a luta contra qualquer retrocesso, pelos direitos e pela democracia.

Certamente, estamos diante da força de movimentos sociais e de uma grade jurídico-legal que produz impacto no cotidiano das relações institucionais brasileiras. No entanto os índices de violência seguem avassaladores, colocando-nos como o 5o país que mais mata mulheres no mundo (Waiselfisz, 2015). O corpo da mulher segue sendo considerado propriedade de um universo masculino que atua cotidianamente, preservando o machismo em prol de um lugar privilegiado na topografia social. Os espaços societários brasileiros conservam hierarquias de classe, gênero e raça mediante a violência de um Estado que pouco se compromete com o exercício da laicidade, da justiça e da igualdade. Nesse âmbito, o corpo-população-mulher pode tanto ser ignorado, explorado e assassinado quanto mantido tal qual uma peça central na engrenagem que sustenta a lógica da propriedade e do capital. Em muitos casos, a morte de mulheres nem sequer é contabilizada ou enquadrada como um assassinato.

Mendes (2016) entende que, mesmo diante do esforço da luta das mulheres por direitos, o aparato estatal é, em regra, violador e revitimizante. A autora afirma que a cultura jurídica brasileira é patriarcal e segue os pilares morais de uma mulher que deve ser "bela, recatada e do lar". A mulher que foge dessa regra é "por princípio" culpada. Resta-nos perguntar: Direitos Humanos para quem? Que humano é esse? Questões que nos levam a pensar nas formas como o campo da Saúde vem produzindo práticas democráticas no encontro com a diversidade de mulheres brasileiras.

De acordo Jelin (1994), essas perguntas são fundamentais para que as mulheres participem ativamente na redefinição permanente do conceito de direitos humanos produzido no enquadramento masculino, branco e ocidental. Torna-se necessário, segundo a autora, disputar pelos conceitos de liberdade e igualdade superando os encargos deixados pelo poder colonial, esse poder microfísico que naturaliza a subordinação e as hierarquias sociais. Para Jelin (1994), talvez tenhamos que nos aproximar da ideia de que direito humano é possuir um lugar no mundo, uma voz legítima, uma terra de pertencimento, um corpo sem a lei cotidiana da violência.

Nessa mesma esfera, Butler (2015) afirma que, antes de pensarmos em direitos humanos, é necessário entender que vivemos em uma geopolítica racista e sexista que define o que é humano e o que deve ser desumanizado continuamente. A autora, desde a escrita de "Problemas de Gênero" (2017), leva-nos a questionar os enquadramentos normativos que se definem a partir de uma divisão binária (masculino versus feminino), diante dos quais algumas vidas valem mais e outras valem menos. Ainda, com Butler (2017), pode-se dizer que essas normas de gênero dizem respeito ao modo como podemos aparecer no espaço público e quais são as condições de regulação que definem quem na pólis é realmente protegido pela lei, quem terá assistência à saúde perante uma situação de abortamento, quem será alvo da perseguição policial, quem terá queixas de violência negadas, ou mesmo quem será culpabilizado por ousar transitar livremente por um espaço branco, conservador, 
cisnormativo e patriarcal. As formas de aparecimento do corpo no público são, para Butler (2017), performatividades de gênero que permitem compreender atos corporais e linguísticos como materialidades que ocorrem no momento da enunciação, acionando um conjunto de efeitos. As forças performativas podem ser corporificadas seguindo os ditames da norma e de um ideal regulado, que requer reconhecimento e legitimidade. Mas não somente. A performatividade pode se corporificar acionando um conjunto de efeitos que se atualizam em um movimento de reivindicação por modos de viver-enunciar-corpo que resistam e destituam forças hierárquicas e excludentes.

As perspectivas de Jelin (1994) e de Butler (2017) nos permitiram compreender a universidade como um espaço público regulado por normas de reconhecimento que produzem efeitos de segregação e violência, mas também de resistência. É nessa arena de lutas que buscamos criar estratégias de ações de combate à violência de gênero no âmbito das festas e ritualizações que desenham a geografia universitária. Encontramos no paradigma da Redução de Danos a possibilidade de produção de uma linha ética de cuidado que articula saúde como prática democrática, o gênero como possibilidade performativa de resistência na pólis e os direitos humanos como direito de existir livre da violência. Com isso, deslocamo-nos das questões puramente morais em relação ao uso de substâncias e criamos equipamentos individuais e coletivos de resistência para que as nossas vidas (de nós mulheres) não sejam "descartáveis" (Butler, 2018). Assim, utilizamos como base para as ações do projeto e discussões teóricas o conceito de assembleia, trazido por Butler como "formas da performatividade corporificada e plural" (2018, p. 14). Assim, ampliando-se a noção de performatividade e pensando-se na organização coletiva, o conceito de assembleia (Butler, 2018) parece ser um aparato teórico importante para pensar a organização de mulheres universitárias em contextos de festas.

\section{A Perspectiva da Redução de Danos}

O uso de drogas, sua produção e consumo são práticas históricas em nossa sociedade. A proibição, criminalização do uso e comércio de algumas drogas, que passaram a ser vistas como ilícitas, datam a partir do século XX, produzindo a conhecida "guerra contra as drogas" e seu caráter punitivo e segregacionista, no qual, em nome da proteção e do cuidado, ". . . as drogas são consideradas como epidemia social e os sujeitos com ela envolvidos, lixo. Um lixo que demanda limpeza e, assim, a legitimação de um 'neo-higienismo'" (Bicalho, Kinoshita, Castilho, \& Carvalho 2013. p. 17). Favorecem, portanto, por parte do estado e da sociedade, práticas de exclusão, violência, que causam sofrimento e que não se mostram efetivas no enfrentamento às problemáticas das possíveis consequências advindas do uso excessivo e/ ou descontrolado de drogas para os indivíduos. As ações em nome da proteção e do cuidado, pautadas na abstinência e internação compulsória como único recurso de tratamento, favorecem o higienismo e não possibilitam a construção de políticas públicas efetivas de intervenções e tratamento (Conselho Federal de Psicologia, 2013), quando se fala em direitos dessas pessoas.

Dessa forma, é possível perceber que muitos dos danos e consequências relacionados ao uso das drogas não têm suas causas na própria droga, mas sim na sua proibição e criminalização. A política de Redução de Danos, partindo dos pressupostos da reforma psiquiátrica, 
busca reduzir os prejuízos biológicos, sociais e econômicos relacionados ao uso de drogas, colocando-se como uma alternativa à segregação e exclusão da loucura, desses sujeitos usuários, vistos muitas vezes como menos humanos. A política se dará, em sua prática, por meio de ações inclusivas que estimulem o protagonismo dessas pessoas, buscando a preservação de seus direitos. Por meio do fato histórico da existência e do uso das drogas e da percepção de que estratégias punitivas não garantem a sua extinção e a saúde dos indivíduos, a política de RD busca realizar um trabalho em conjunto com cada indivíduo usuário, de modo a pensar e ofertar estratégias de acompanhamento visando ao cuidado de si, tendo como foco o respeito aos indivíduos e suas singularidades, e não focalizando, portanto, na substância (Conselho Federal de Psicologia, 2013).

A política de Redução de Danos passa por diferentes espaços de discussão e estratégias de cuidado, no âmbito da Saúde Coletiva, como a oferta de seringas descartáveis para o uso de drogas injetáveis, distribuição de cachimbos individuais, distribuição de água e oferta de ambientes arejados em festas, pensando possíveis problemas ocasionados pelo uso de álcool e/ou outras substâncias, de forma que busca, assim, de diferentes formas, reduzir as consequências adversas desse consumo. Em se tratando de práticas educativas, busca-se pensar estratégias informativas com base em fatos, fundamentadas em pesquisas, a partir das vivências da população-alvo, uma vez que estratégias amedrontadoras, punitivas, afastam-se do real e não se mostram efetivas (Conselho Federal de Psicologia, 2013).

No Brasil, existem alguns projetos e coletivos baseados nos princípios da Redução de Danos, sendo eles: Balanceara (Ceará), Celebrate e Noosfera (Rio Grande do Norte), Recifree (Pernambuco), Balance, Se Plante, Ar-Te-Cura, Test (Bahia), Egrégora (Minas Gerais), Associação Psicodélica do Brasil (APB) (Rio de Janeiro), Psicodelizando, Respire (São Paulo), Fique Legal, Vivência RD (Santa Catarina), Lottus, Changa (Rio Grande do Sul), Luz Azul, Repense (Curitiba-Paraná) ${ }^{3}$. Esses coletivos trabalham na perspectiva de Redução de Danos e do antiproibicionismo, com foco no contexto da festa e testagem das substâncias psicoativas, entendendo a importância da informação e do conhecimento sobre a substância que se ingere, de modo a pensar os efeitos desta sobre o corpo e possibilitar que se saiba como agir em uma abordagem de risco, nos casos em que se faz necessário. A abordagem parte, ainda, da importância de pensar a relação da história de vida pessoal dos(as) usuários (as) e suas expectativas em relação ao cenário das festas. Outro foco de alguns desses grupos é a criação de um setting, no qual os(as) usuários(as) podem buscar ajuda em um momento no qual se sintam inseguros em relação aos efeitos do uso e possam ser acolhidos, sem moralização e preconceito por parte dos organizadores (Conselho Federal de Psicologia, 2018). Partindo da existência desses coletivos e do alto índice de denúncias de assédio, violência sexual, entre outros tipos de violência que ocorrem no contexto universitário, criam-se condições de possibilidade para a construção de um projeto no contexto das festas universitárias, em uma universidade estadual, localizada em uma cidade de pequeno porte do interior do Paraná, a partir da perspectiva da Redução de Danos com recorte de gênero. É o que discutiremos no próximo tópico.

\footnotetext{
${ }^{3}$ Hempadão. Redução de danos em contexto de festa: Capacitação no Rio de Janeiro, 2017. Recuperado de http://hempadao.com/reduo-de-danos-em-contexto-de-festa-capacitao-no-rio-de-janeiro/
} 


\section{Redução de Danos com Recorte de Gênero}

No ambiente das festas universitárias, a utilização e o fornecimento do álcool e de outras drogas necessitam ser discutidos a partir da materialização das masculinidades e feminilidades na relação com práticas de violência contra a mulher. Desta forma, coloca-se em pauta a criação de práticas de redução de risco e dano relacionadas aos possíveis modos como as mulheres enfrentam a violência, vivenciam a autonomia dos seus próprios corpos, bem como exercitam os direitos que lhe são próprios no universo das festas acadêmicas. Reduzir riscos e danos no campo da violência de gênero envolve também um conjunto de princípios e ações para a abordagem dos problemas relacionados ao uso de álcool e outras drogas na cena das festas. Trata-se de uma perspectiva transdisciplinar de saúde, cultura, educação e assistência social, visando à garantia do cuidado e dos direitos. Torna-se fundamental ressaltar que essa perspectiva não realiza ações voltadas para abstinência, ou mesmo para a culpabilização ou moralização dos atores que frequentam as confraternizações.

Na cena-festa, o que se busca é convocar as mulheres a se reconhecerem como protagonistas na produção do exercício político e público dos seus próprios corpos. Isso implica a desnaturalização da ideia da mulher como objeto de violência, desvalor. A relação corpo- autoria-direito abre passagem para um campo de intervenção composto por pelo menos três eixos. O primeiro deles remete a práticas informativas e de reflexão que colocam em pauta o modo como as mulheres se reconhecem e são hegemonicamente reconhecidas na cena da festa universitária contemporânea. Entra em pauta a desnaturalização das lógicas de um corpo que pode ser assediado, da mulher que merece ser estuprada porque bebeu, da mulher que "diz não, mas na verdade diz sim", da mulher que usa drogas e, portanto, quer "liberar tudo", da mulher que só se sente feliz nas festas quando é assediada.

A segunda arena de intervenção se concentra nas lógicas cristalizadas que configuram o que e como uma estudante deve ser, fazer e pensar ao entrar na universidade: participar de festas, exercitar determinadas práticas de socialização, tais como beber, experimentar certas substâncias, experienciar o corpo sexualmente, práticas essas que são, muitas vezes, a "senha de entrada" para a vida universitária, constituindo-se em um modelo rígido e linear das tramas do pertencimento na universidade. Em alguns casos, os/as estudantes são coagidos/as a participar de trotes, que são uma espécie de "ritual de passagem", com o objetivo, inicial de celebrar a chegada de novos alunos, mas que podem vir a se tornar violentos, dependendo das práticas propostas. As chamadas "cachoeirinhas" e "goles" fazem parte da ritualização festiva, não se trata de negá-las, ou mesmo demonizá-las. O que se pretende é afirmar o exercício da liberdade e da dignidade da mulher no contexto acadêmico. Nestes casos, a Redução de Danos atua colocando em questão a forma como os organizadores das festas/trotes pensam e se corresponsabilizam com a dignidade e autonomia das frequentadoras da festa. No mesmo movimento, atua para que as mulheres possam exercitar a possibilidade de escolha em relação à participação nos trotes, bem como de afirmar outros tantos modos de experienciar-se nas festas.

O terceiro eixo de trabalho se volta para as formas de autocuidado na cena-festa. Não se trata de dizer não ao uso de álcool e outras drogas, mas sim de abordar as formas como estudantes se relacionam com esse uso. Neste campo, a Redução de Danos atua produzindo e divulgando material informativo sobre prevenção e sobre os efeitos que determinadas 
maneiras de usar certas substâncias, tanto lícitas como ilícitas, podem produzir no corpo. Desse modo, a informação se volta para as práticas de hidratação, alimentação, efeito-quantidade, efeito-mistura entre substâncias, efeito-tipo de substância. Informações sobre a rede de serviço e atendimento em caso de uma intoxicação ou superdosagem também é parte desse processo. A pauta se volta para o autocuidado e a possibilidade de acesso aos serviços de acolhimento, sem que qualquer tipo de moralização, culpabilização, medo e silenciamento faça parte do processo.

\section{Aspectos Metodológicos}

Os aspectos teórico-metodológicos que sustentaram as ações do projeto de extensão relatadas neste artigo colocam-se, como dito anteriormente, na articulação entre a perspectiva da Redução de Danos e dos Direitos Humanos, com recorte de gênero. Organizamos as ações em quatro eixos: 1) atividades de capacitação da equipe executora do projeto; 2) ações de divulgação na universidade, bem como junto aos organizadores de festas universitárias; 3$)$ intervenções em cenários de festa visando a ações de educação informativa sobre os modos de se relacionar com o uso de álcool e outras substâncias em contextos festivos da universidade; 4) realização de grupos visando à sensibilização das estudantes que frequentam as festas para a criação de estratégias de prevenção e promoção de práticas de cuidado coletivas.

O público-alvo direto foi composto por acadêmicas de um campus de uma universidade estadual do Paraná, mas também se buscou atingir, por meio das ações de intervenção em festas, acadêmicos e frequentadores em geral, comunidade e organizadores de eventos. Os cursos envolvidos foram prioritariamente psicologia, história, letras, pedagogia, geografia, fonoaudiologia, engenharia florestal e ambiental, entre outros cursos existentes no campus. O projeto de extensão, desdobrado em duas pesquisas que fizeram coletas de dados e intervenções nas festas e nos grupos realizados com acadêmicas, foi aprovado segundo pareceres do Comitê de Ética em Pesquisa institucional (COMEP/UNICENTRO), conforme números 91507518.3.0000.0106 e 90576418.4.0000.0106.

Como descrito anteriormente, o projeto organizou-se em vários eixos, entretanto, para este artigo, optamos por discorrer acerca das estratégias utilizadas durante intervenções realizadas em festas universitárias. As ações organizaram-se primeiramente em uma fase formativa, em que a equipe executora discutiu textos relacionados aos eixos teóricos que embasaram o projeto, para, a seguir, produzirem materiais que seriam utilizados nas intervenções com a comunidade. Assim, produziu-se uma cartilha intitulada "Redução de Danos no Rolê", que continha informações sobre o projeto, sobre os direitos da mulher, estratégias de autocuidado e cuidado coletivo sob a perspectiva da Redução de Danos e, ainda, informações sobre locais para procurar ajuda em situações de violência ou de abuso de álcool ou outras substâncias.

A equipe foi composta por duas professoras e oito acadêmicas do curso de graduação em Psicologia, e atuou por meio de intervenções em cinco festas universitárias durante o ano de 2018. As ações eram iniciadas desde a divulgação da festa, a partir da disseminação da proposta de uma festa que atuasse na prevenção à violência contra a mulher. No contexto festivo, utilizamos materiais como a cartilha produzida pela equipe, disponibilizada impressa 
em tamanho de folder e por meio de varal (cartazes), além de outros materiais, como um carimbo com a frase "não é não" e, ainda, estratégias de disponibilização, durante a venda dos ingressos ou na entrada da festa, de informações acerca da prevenção da violência. Dentro da proposta de Redução de Danos, houve distribuição de água; prevenção por meio de conversa e contato com as pessoas (homens e mulheres); e organização de um espaço para acolher e encaminhar mulheres, buscando incentivar o autocuidado e o cuidado coletivo.

Após cada intervenção, a equipe se reunia para avaliar ações e apresentar restituição aos proponentes da festa.

\section{Resultados e Discussão}

Como resultado da execução do projeto, abordaremos dois eixos de análise. O primeiro, em relação à elaboração do projeto e sua perspectiva metodológica, e o segundo, em relação à análise discursiva do corpo da mulher no cenário da festa, tomando como base o conceito de assembleia, apresentado por Butler (2018).

Por meio de leituras e discussões de assuntos referentes à temática do projeto, preparouse a equipe para atuar no cenário das festas universitárias sob a perspectiva da Redução de Danos com recorte de gênero e articulação com os Direitos Humanos. A partir da capacitação, a equipe produziu uma cartilha para ser utilizada como material educativo e de divulgação do projeto. Esse material, com uma linguagem adequada ao público-alvo das intervenções, apresentava informações sobre a discussão do assédio e violência sexual no ambiente universitário, nomeação de diferentes tipos de violência, estratégias de autocuidado e cuidado coletivo, bem como informações de ambientes onde as mulheres poderiam procurar ajuda em casos de violência, mostrando-se um importante instrumento que foi utilizado em diferentes ações realizadas pela equipe.

A atuação interventiva em cinco festas universitárias iniciou-se com contato e reunião com os/as organizadores/as para apresentação do projeto e discussão das práticas interventivas nas festas, visando à sensibilização e ao comprometimento ético-político dos/as organizadores/as em relação à temática da violência contra mulher no contexto das festas universitárias. As ações se deram em diferentes momentos, desde a divulgação da festa nas redes sociais, no momento da entrega do ingresso, havendo reconhecimento da presença do projeto "Redução de Danos no Rolê" como algo que agregava uma característica diferente ao evento festivo. Ou seja, trazia como efeito discursivo um "rolê" que tinha preocupação com a segurança e saúde das mulheres.

No contexto da festa, a utilização de materiais como a cartilha e o carimbo com a frase "não é não" provocou a reflexão acerca da prevenção e da noção de consentimento, colocando em pauta as discussões relacionadas a gênero e violência. A distribuição de água e de um espaço para acolhimento de jovens que, eventualmente, precisavam de ajuda constituiu fundamentalmente a relação com a perspectiva da Redução de Danos. Para além disso, durante o período de realização do projeto, recebemos a solicitação da participação da equipe organizadora em festas universitárias e solicitação dos materiais produzidos para utilização em festas que não contaram com a participação da equipe.

Ainda dentro desse primeiro eixo de análise, foi necessário considerar o fato de a equipe ser composta por mulheres, o que coloca em discussão o corpo da mulher em risco, uma vez 
que existia a exposição das mulheres nas intervenções, sem o respaldo dos organizadores no que toca à questão da segurança e mesmo integridade física dessas mulheres. Esse é um dos motivos pelos quais as intervenções aconteciam no início das festas, caracterizando-se como um trabalho preventivo, o qual visava à conscientização dos atores envolvidos no cenário das festas, sendo disponibilizadas informações referentes à temática da violência contra a mulher, nomeação dos tipos de violência, locais para procurar ajuda em casos de violência e estratégias de autocuidado e cuidado coletivo. Essa questão nos convoca a pensar que, ao final das festas, poderia ser realizado um trabalho mais interventivo em relação à segurança das mulheres, levando em conta que o cenário da festa cria condições para que as mulheres se encontrem embriagadas; contudo a responsabilidade pela segurança e integridade de seus corpos é exclusivamente delas. Em relação aos organizadores, por vezes apresentavam expectativas divergentes em relação à proposta do projeto, como a expectativa de um trabalho "policialesco", frequentemente demandando a fiscalização de homens por parte da equipe - demanda essa que não era atendida e era discutida posteriormente, quando se fazia uma reunião com organizadores para dar-lhes uma devolutiva acerca da intervenção.

No que tange ao segundo eixo de discussão desta análise, referente ao corpo da mulher no cenário das festas universitárias, as intervenções possibilitaram a percepção de que, em sua maioria, no contexto deste projeto, as mulheres universitárias são jovens, brancas e de classe média. O ambiente da festa se caracteriza como heteronormativo, existindo uma divisão binária no banheiro, nas letras das músicas, nas vestimentas e nos materiais publicitários expostos. Essa questão foi materializada em uma das festas em que havia uma pessoa vestida de mascote da Atlética performando feminilidade, a partir de elementos como estar vestida de salto e maquiada, de modo que causou estranhamento quando precisou utilizar o banheiro, devido à performatividade diferente da "norma" estabelecida no contexto. Outro aspecto perceptível em relação à norma das mulheres que frequentam essas festas é que mulheres negras e pardas compareciam a esse cenário prioritariamente em serviços gerais, limpeza etc., elemento importante para pensar que o recorte de gênero carece ainda da consideração pelo viés da interseccionalidade (Hirata, 2014).

Para discutir o lugar do corpo da mulher no cenário das festas universitárias, é preciso levar em conta que ele é, desde sempre, objeto de vigilância e regramento (Beauvoir, 2016). Nas universidades, mais especificamente das festas universitárias, campo de intervenção do projeto, existem diferentes discursividades em relação à mulher. As festas nas quais realizamos as intervenções são ligadas aos centros acadêmicos, coletivos e movimentos sociais que ensaiam práticas de prevenção à violência e segurança para as mulheres nesses ambientes. No entanto não estão livres de práticas de violação e regramento em relação à mulher e, desta forma, aceitaram ou convocaram a participação da equipe do projeto.

No cenário da festa, existem regras de funcionamento que dão lugares aos corpos: são corpos consumidores e objetos de consumo e colocam-se diferentemente em função das relações de gênero. As diferenças entre homens e mulheres se materializam desde o momento da chegada na festa. Estas, em sua maioria, chegam acompanhadas de outras mulheres, com parceiro ou parceira; raramente chegam sozinhas. Os homens, em sua maioria, chegam sós. É esperado da mulher a performatividade da feminilidade, seja a partir das roupas, seja a partir da dança, com movimentos sensuais que materializam uma sexualidade que está ali para ser mostrada. Além disso, a esses elementos é adicionada a condição de possibilidade 
de embriaguez, que torna as participantes das festas vulneráveis, mas sempre performando um corpo que se coloca como objeto de desejo, propenso ao assédio, ao toque, à sexualização. Dos homens, é esperada a performatividade da virilidade: olhar altivo, postura ereta, superior, não havendo possibilidade de demonstrar nenhum sinal de fragilidade. Nesse sentido, a prática de assédio e a violência são vistos como algo viril. Tais observações permitem a análise de que, em nossa sociedade, assim como no recorte das festas, os homens precisam se privar de sua feminilidade, assim como as mulheres precisam se privar de sua virilidade (Despentes, 2016). Os corpos e suas ações são demarcados por esses parâmetros.

As relações se constroem de forma que as mulheres podem escolher um parceiro, entretanto o que se coloca é um jogo no qual elas precisam colocar-se como "desejáveis", produzindo, por meio dos seus corpos, uma prática discursiva na qual o homem possa performar sua virilidade, tendo-se como efeito que é o homem que protagoniza a cena: é ele quem escolhe. Há outras possibilidades além da que coloca a mulher no lugar de objeto de desejo (e não sujeito), contudo a leitura que se faz daquela que se autoriza a decidir sobre a sua sexualidade e prazer está fora do estatuto da mulher considerada "respeitável".

Esse mesmo paradoxo que coloca os limites entre a liberdade que pode ser exercida pela mulher no cenário das festas e o código de conduta aceitável, dá-se em relação ao consumo de bebida alcoólica. Grande parte das festas em que foram feitas as intervenções do projeto eram do tipo open bar, ou seja, com bebida liberada, elemento discursivo que convoca ao consumo. Mesmo quando as mulheres pagavam o ingresso das festas, o valor era convertido em consumo. Desse modo, teoricamente, o consumo de bebidas era comum a todas/ todos, sendo que tanto homens quanto mulheres dirigiam-se até o bar para pegá-las. Outro aspecto importante é que, na maioria das festas, não havia venda de produtos alimentícios, mas consumo quase exclusivo de bebidas alcoólicas. Havia, ainda, o consumo de cigarro por homens e mulheres e possivelmente consumo de outras substâncias, mas que, por serem ilegais, não eram consumidas em frente aos demais participantes da festa.

O consumo de bebida, nesses contextos, portanto, coloca o corpo feminino dentro de uma regra, que é a de consumir: praticamente não é possível estar na festa sem beber, podendo ocorrer, inclusive, situações de coerção. Ainda, água ou refrigerante, por exemplo, não estão entre as bebidas que podem ser consumidas à vontade, de modo que são criadas condições para corpos embriagados. As consequências do consumo exacerbado ou do não conhecimento dos limites do próprio corpo (algo que é significado como de responsabilidade exclusiva individual) são silenciadas, mas é cobrado da mulher que beba dentro dos limites para se apresentar como um corpo desejável, e não um corpo demasiadamente bêbado, sob pena de ser retirado da festa ou ainda colocar-se como um corpo potencialmente violável.

Assim, podemos dizer que, mesmo em festas universitárias, pretensamente ligadas a ideais de liberdade, de igualdade de gênero, ainda cabe a premissa: "Sejamos livres, mas não muito" (Despentes, 2016, p. 17). A mulher pode ocupar o espaço da festa, mas sempre acompanhada. Pode utilizar uma roupa curta, mas não sem medo. Pode ingerir bebidas alcoólicas ou outras substâncias, mas não sem culpa, especialmente em casos de assédio, estupro ou outras formas de violência. Em suma, podem ocupar esse espaço, mas "nunca iguais com nossos [seus] corpos de mulheres, nunca em segurança" (Despentes, 2016, p. 28). Podemos dizer, portanto, que é simplesmente por serem mulheres que estão vulneráveis e ocupam 
diferentemente o espaço público, de modo que, nos casos em que acontecem violências e as mulheres as denunciam, a palavra delas sempre é colocada em dúvida, ou ainda são responsabilizadas e culpadas pela violência que vivenciaram.

Por fim, é necessário falar sobre a importância da nomeação das violências e sobre a prática que mulheres e homens têm de contornar o termo, não falando sobre estupro, por exemplo, que é tomado como algo que pode acontecer ". . . quando se é mulher e se deseja correr o risco de se aventurar do lado de fora" (Despentes, 2016, p. 36). Assim, o crime é naturalizado, já que ". . . estupros acontecem o tempo todo. Eis aqui um aglutinador, que conecta todas as classes sociais, idades, corpos e personalidades" (Despentes, 2016, p. 29). A mesma autora questiona o fato de nós, mulheres, não falarmos sobre a violência e não compartilharmos o saber adquirido a partir das nossas vivências, nomeado por ela como "estratégias de sobrevivência". Essa questão apareceu nas discussões que permeavam a análise das intervenções nas festas, por meio da pergunta "Por que sempre nós e não eles?", em que as participantes questionaram o fato de as mulheres serem ensinadas a se proteger e não haver uma mudança de postura por parte dos homens. É neste sentido que as práticas de autocuidado e cuidado coletivo surgem como uma estratégia encontrada por essas mulheres e como forma de prevenção, como uma possibilidade de (r)existir no espaço público, e não simplesmente deixar de frequentá-lo. Contudo a equipe do projeto, durante as intervenções, compreendeu que deixar de frequentar alguns espaços específicos em que ocorrem práticas de violência pode ser uma opção.

Partindo disso, é possível compreender que não existe, de fato, uma apropriação do espaço público pelas mulheres (Despentes, 2016), ainda que, nas festas em que participamos, elas circulem, ocupando o lugar de organizadoras, trabalhadoras, interventoras. É esperado que o corpo da mulher esteja em movimento no cenário da festa, aparentemente livre, entretanto essa pretensa liberdade é cerceada pelos critérios de segurança, a qual não é garantida, sendo de responsabilidade da própria mulher.

Nesse cenário de responsabilização/culpabilização/justificação da violência, é preciso pensar, entretanto, em formas de resistência, de modo que a mulher possa ocupar o espaço público, vestindo-se da maneira que desejar e circulando e movimentando-se no espaço (nesse caso, nas festas) como quiser. Parece pertinente trazer para essa discussão o conceito de assembleia, cunhado por Butler (2018). A ideia de assembleia é concebida pela autora a partir dos movimentos sociais empreendidos por grupos denominados por ela como "vidas precárias" e "corpos vulneráveis", que, ao se unirem em um espaço público, "estão exercitando um direito plural e performativo de aparecer, um direito que afirma e instaura o corpo no meio do campo político" (Butler, 2018, p. 17). Essa reunião de corpos, conforme discutido pela autora, apresenta uma discursividade significativa, para além do que é dito, mesmo que em silêncio. Esses grupos trazem no corpo a exigência de condições econômicas, sociais e políticas de existir, ocupar os espaços, sem temer ou sofrer violência.

Esses movimentos de performatividade plural podem ser compreendidos também ao pensarmos as formas de resistência organizadas por grupos de mulheres. No cenário das festas universitárias, essas formas de resistência podem ser pensadas a partir de ações como problematizar condições distintas para mulheres (entrada de graça, bebida à vontade), organizar-se para ir e voltar em grupo das festas; também, poderíamos pensar em boicotes 
(virtuais ou não) a eventos e/ou práticas comuns nesses eventos. Tendo em vista que os eventos são, na maioria das vezes, organizados a partir de uma lógica masculina, para agradar ao público masculino, as mulheres começam a questionar, organizando-se em grupo para imprimir outra lógica nesses espaços. É esse mapeamento e potencialização das pequenas resistências que o grupo organizado a partir do Projeto "Redução de Danos no Rolê" procurou fazer.

\section{Considerações Finais}

O projeto que apresentamos por meio deste artigo teve o objetivo de promover reflexão e discussão acerca da temática da violência contra a mulher nas festas universitárias. Dada a temática e diversidade das ações, acabou abrindo a possibilidade da discussão de dois principais eixos: o corpo da mulher no cenário das festas universitárias e as práticas de autocuidado e cuidado coletivo desenvolvidas para e por mulheres. Os eixos de discussão decorreram das duas grandes frentes de ações do projeto de extensão: as intervenções nas festas universitárias e os grupos realizados com mulheres na universidade. Neste artigo, optamos por apresentar os resultados concernentes às intervenções nas festas universitárias apenas.

Foi possível perceber alcance e repercussão entre a comunidade acadêmica e fora dela, o que foi potencializado pela Internet, que colocou em cena também nas redes as ações realizadas. As intervenções nas festas produziram diferentes efeitos, tanto no público participante quanto na equipe executora, de forma que, no decorrer do projeto, as ações foram sendo transformadas em função das reflexões possibilitadas a partir de cada intervenção. Isso diz respeito, sobretudo, ao aspecto formativo das acadêmicas de Psicologia que participaram da equipe executora do projeto de extensão.

Outro resultado significativo das ações no cenário das festas foi a solicitação por parte dos organizadores da presença da equipe do projeto em suas festas, bem como da disponibilização dos materiais produzidos pela equipe para a utilização em festas nas quais não poderíamos participar. Entendemos que as ações do projeto possibilitaram a instauração de uma cultura de cuidado em relação à prevenção da violência contra as mulheres, pelo menos no que diz respeito às festas universitárias.

Destacamos o caráter inovador do projeto ao articular a perspectiva de Gênero, Direitos Humanos com Redução de Danos, no âmbito do contexto de festas universitárias, o que, ao nosso ver, criou condições de possibilidade para a reflexão acerca de estratégias de autocuidado e cuidado coletivo entre as mulheres, uma vez que se partiu de uma perspectiva não culpabilizadora das participantes que se inserem nesses cenários festivos. Essa perspectiva endossa o protagonismo das mulheres, o que trouxemos neste texto a partir da noção de assembleia, cunhada por Butler (2018). Por fim, é preciso deixar claro que a noção de assembleia, conforme proposta por Butler (2018), implica ações relacionadas a corpos que se unem e performam de diferentes maneiras. São ações plurais, muitas vezes com propósitos convergentes e divergentes. Nesse sentido, agir em conjunto não significa necessariamente agir em conformidade, mas diz respeito a uma noção de corpos se movimentando em muitas direções. 


\section{Referências}

Beauvoir, S. (2016). O segundo sexo (S. Milliet, trad.). Rio de Janeiro: Nova Fronteira.

Bicalho, P. P. G., Kinoshita, R. T., Castilho, E. W. V., \& Carvalho, G. (2013). Em nome da proteção do cuidado, que formas de sofrimento e exclusão temos produzido? Conselho Federal de Psicologia. Drogas, direitos humanos e laço social (1a ed.). Brasília-DF: CFP. Recuperado de https://site.cfp.org.br/wp-content/uploads/2013/07/Drogas-Direitos-Humanos-eLaco-Social.pdf

Brasil. (1988). Constituição da República Federativa do Brasil (21a ed.). São Paulo: Saraiva.

Brasil. (2006). Lei 11.340 (7 de agosto). Cria mecanismos para coibir a violência doméstica e familiar contra a mulher. Brasília-DF. Recuperado de http://www.planalto.gov.br/ ccivil_03/_ato2004-2006/2006/lei/l11340.htm

Brasil. (2016). Código Civil e normas correlatas (7a ed.). Brasília-DF: Senado Federal. Recuperado de http://www2.senado.leg.br/bdsf/handle/id/525763

Butler, J. (2017). Problemas de gênero: Feminismo e subversão da identidade (13a ed.). Rio de Janeiro: Civilização Brasileira.

Butler, J. (2018). Corpos em aliança e a política das ruas: Notas para uma teoria performativa de assembléia. Rio de Janeiro: Civilização Brasileira.

Butler. J. (2015). Quadros de guerra: Quando a vida é passível de luto? Rio de Janeiro: Civilização Brasileira.

Conselho Federal de Psicologia. (2013). Drogas, direitos humanos e laço social. BrasíliaDF: CFP. Recuperado de https://site.cfp.org.br/wp-content/uploads/2013/07/DrogasDireitos-Humanos-e-Laco-Social.pdf

Conselho Regional de Psicologia. (2018). Mesa-redonda sobre redução de danos em contextos de festas. Recuperado de https://www.facebook.com/crppr/videos/1536648396384078/ Costa, A. M. (2009). Participação social na conquista das políticas de saúde para mulheres no Brasil. Ciência e Saúde Coletiva, 14(4), 1073-1083. Recuperado de http://www.scielo.br/ scielo.php?script=sci_arttext\&pid=S1413-81232009000400014\&lng=en\&nrm=iso

De Tilio, R. (2012). Marcos legais internacionais e nacionais para o enfrentamento à violência contra as mulheres: Um percurso histórico. Revista Gestão e Políticas Públicas, 1(2), 68-93.

Despentes, V. (2016). Teoria King Kong (M. Bechara, Trad.). São Paulo: n-1 edições.

Dias, M. B. (2017). Manual de direito das famílias (12a ed.). São Paulo: Revista dos Tribunais. Hirata, H. (2014). Gênero, classe e raça: Interseccionalidade e consubstancialidade das relações sociais. Tempo social - Revista de Sociologia da USP, 26(1), 61-73.

Instituto Avon, \& Data Popular. (2015). Violência contra a mulher no contexto universitário. Recuperado de http://www.ouvidoria.ufscar.br/arquivos/PesquisalnstitutoAvon_v9_ FINAL_BX20151.pdf

Jelin, E. (1994). Mulheres e direitos humanos Revista Estudos Feministas, 2(3), 117. Recuperado de https://periodicos.ufsc.br/index.php/ref/article/view/16293/14834

Mendes, S. R. (2016). Justiça penal e justiça da família: A guarda compartilhada e a proteção que desprotege. RDU, (Especial), 167-181. Recuperado de https://docs.wixstatic.com/ ugd/6abd45_f471fa71539145cd8f55614593e79095.pdf.

Santos, K. A., \& Zarpellon, B. C. O. (2019). (D)enunciar a violência contra a mulher na universidade: Uma análise discursiva. In H. D. Lau, E. L. da Silveira, Raça, gênero e 
sexualidade em perspectivas discursivas: Teorias e análises (pp. 74-92). São Paulo: Pimenta Cultural.

Secretaria de Políticas para as Mulheres. (2005). Plano Nacional de Políticas para as Mulheres.

Secretaria de Políticas para as Mulheres. Brasília-DF. Recuperado de https://bvsms.saude. gov.br/bvs/publicacoes/pnpm_compacta.pdf

Waiselfisz, J. (2015). Mapa da Violência 2015. Homicídio de mulheres no Brasil. Brasília:

Unesco. Recuperado de www.mapadaviolencia.org.br

\section{Sobre as autoras :}

Recebido em: 27/07/2019 última revisão: 12/05/2020

Aceite final: 19/05/2020

Katia Alexsandra dos Santos: Doutora em Psicologia pela Universidade de São Paulo (USP). Professora adjunta do curso de Psicologia, da Universidade Estadual do Centro-Oeste (UNICENTRO). E-mail: kalexsandra@unicentro.br, Orcid: http://orcid.org/0000-0003-4706-6624.

Paula Marques da Silva: Doutora em Educação e mestra em Psicologia Social e Institucional pela Universidade Federal do Rio Grande do Sul (UFRGS). Professora do Departamento de Psicologia da Universidade Estadual do Centro-Oeste (UNICENTRO). E-mail: pmspsicologia@gmail.com,Orcid: http://orcid.org/0000-0003-0159-1052

Bianca Carolline Oconoski Zarpellon: Graduada em Psicologia. Universidade Estadual do Centro-Oeste (UNICENTRO). E-mail: bizarpellon@gmail.com, Orcid: http://orcid.org/0000-0003-0159-1052 
